\title{
Correction: Michaels, H.; et al. Copper Complexes with Tetradentate Ligands for Enhanced Charge Transport in Dye-Sensitized Solar Cells. Inorganics 2018, 6, 53
}

\author{
Hannes Michaels ${ }^{1}\left(\mathbb{D}\right.$, Iacopo Benesperi ${ }^{1}\left(\mathbb{D}\right.$, Tomas Edvinsson ${ }^{2}\left(\mathbb{D}\right.$, Ana Belén Muñoz-Garcia ${ }^{3}$, \\ Michele Pavone ${ }^{4}$, Gerrit Boschloo ${ }^{1}$ (D) and Marina Freitag ${ }^{1, *}$ \\ 1 Department of Chemistry, Ångström Laboratory, Uppsala University, Box 523, SE-75120 Uppsala, Sweden; \\ hannes.michaels@kemi.uu.se (H.M.); iacopo.benesperi@kemi.uu.se (I.B.); gerrit.boschloo@kemi.uu.se (G.B.) \\ 2 Department of Solid-state Physics, Ångström Laboratory, Uppsala University, Box 534, SE-75121 Uppsala, \\ Sweden; Tomas.Edvinsson@angstrom.uu.se \\ 3 Department of Physics "Ettore Pancini”, University of Naples Federico II, 80126 Naples, Italy; \\ anabelen.munozgarcia@unina.it \\ 4 Department of Chemical Sciences, University of Naples Federico II, 80126 Naples, Italy; \\ michele.pavone@unina.it \\ * Correspondence: marina.freitag@kemi.uu.se
}

Received: 14 October 2019; Accepted: 14 October 2019; Published: 29 October 2019

The authors express their sincere apologies to all readers of abovementioned article as mistakes were found upon discussion of the article with colleagues. Hence, we wish to amend the following corrections to the paper [1]:

1. The second row of data in Table 1 should be edited as follows to attain consistency with the graphs presented in Figure 5:

Table 1. $J-V$ characteristics for $\mathrm{Y} 123$-sensitized solar cells with $\mathrm{Cu}(\mathrm{tmby})_{2}$ and $\mathrm{Cu}$ (oxabpy) electrolyte under full AM $1.5 \mathrm{G}$ and under 10\% light intensity. For detailed characterization, the reader is referred to Figures S6-S9 in the Supporting Information.

\begin{tabular}{|c|c|c|c|c|}
\hline Electrolyte & $V_{o c}(\mathrm{mV})$ & $J_{\mathrm{sc}}\left(\mathrm{mA} \cdot \mathrm{cm}^{-2}\right)$ & Fill Factor & PCE (\%) \\
\hline $\mathrm{Cu}(\mathrm{tmby})_{2}$ & 1040 & 10.5 & 0.71 & 7.8 \\
\hline $10 \%$ light & 875 & 1.44 & 0.78 & 10.0 \\
\hline $\mathrm{Cu}$ (oxabpy) & 920 & 9.75 & 0.69 & 6.2 \\
\hline $10 \%$ light & 855 & 1.32 & 0.79 & 8.9 \\
\hline
\end{tabular}

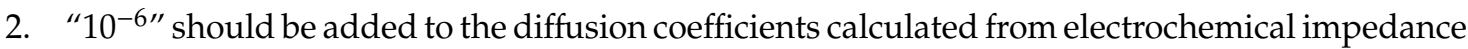
spectroscopy (Section 2.6). These values were correctly stated in Table 4.

"Diffusion coefficients in the redox electrolytes were deduced from the fitted diffusion resistances $R_{W}$ according to Equation (5). The estimated diffusion coefficient for the diffusion-limiting $\mathrm{Cu}^{\mathrm{II}}(\mathrm{tmby})_{2}$ of $22.4 \times 10^{-6} \mathrm{~cm}^{2} / \mathrm{s}$ was found in excellent agreement with previously reported values and supports the proposed equivalent circuit model $[20,41]$. A similar circuit model was applied to fit the impedance spectrum of $\mathrm{Cu}$ (oxabpy). The agreement between experimental data and the equivalent circuit fit indicated that diffusive mass transport was the determining charge transport mechanism. The obtained diffusion coefficient for $\mathrm{Cu}^{\mathrm{II}}$ (oxabpy) of $63.7 \times 10^{-6} \mathrm{~cm}^{2} / \mathrm{s}$ exceeded the diffusion coefficient of $\mathrm{Cu}^{\mathrm{II}}(\mathrm{tmby})_{2}$ by a factor of 2.8."

3. The molar amounts and weights of $\mathrm{CuTFSI}_{2}$ and 6,6'-bis(4-(S)-isopropyl-2-oxazolinyl)2,2'-bipyridine were incorrectly stated in Materials and Methods, and should be corrected as follows. 
"Cu${ }^{\text {II }}$ (oxabpy) was synthesized by reacting CuTFSI 2 (779.75 mg, 1.25 mmol) with 6,6'-bis(4-(S)-isopropyl-2-oxazolinyl)-2,2'-bipyridine $(567 \mathrm{mg}, 1.5 \mathrm{mmol})$ in acetonitrile at $70{ }^{\circ} \mathrm{C}$ for $12 \mathrm{~h} . "$

4. The probe wavelength of $720 \mathrm{~nm}$ should be added in Materials and Methods "Transient Absorption Spectroscopy".

"The sample response was analyzed at $720 \mathrm{~nm}$ with an L920 detection unit (Edinburgh Instruments, Livingston, UK) containing a monochromator, an R928 photomultiplier, and a TDS 3052B oscilloscope (Tektronix, Beaverton, OR, USA)."

\section{Reference}

1. Michaels, H.; Benesperi, I.; Edvinsson, T.; Muñoz-Garcia, A.B.; Pavone, M.; Boschloo, G.; Freitag, M. Copper complexes with Tetradentate Ligands for Enhanced Charge Transport in Dye-Sensitized Solar Cells. Inorganics 2018, 6, 53. [CrossRef]

(C) 2019 by the authors. Licensee MDPI, Basel, Switzerland. This article is an open access article distributed under the terms and conditions of the Creative Commons Attribution (CC BY) license (http://creativecommons.org/licenses/by/4.0/). 